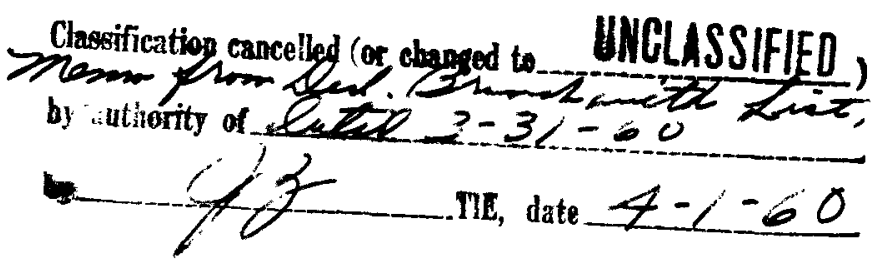

September 20, 1957

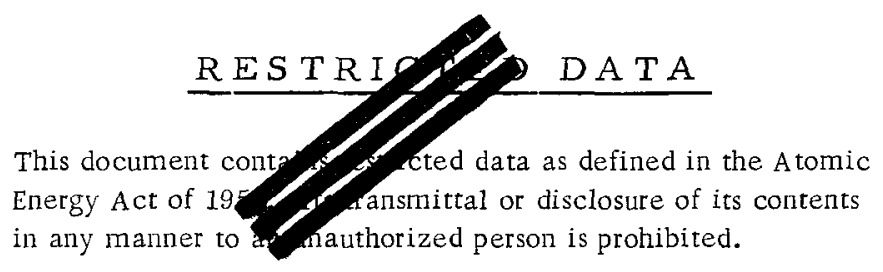




\section{DISCLAIMER}

This report was prepared as an account of work sponsored by an agency of the United States Government. Neither the United States Government nor any agency Thereof, nor any of their employees, makes any warranty, express or implied, or assumes any legal liability or responsibility for the accuracy, completeness, or usefulness of any information, apparatus, product, or process disclosed, or represents that its use would not infringe privately owned rights. Reference herein to any specific commercial product, process, or service by trade name, trademark, manufacturer, or otherwise does not necessarily constitute or imply its endorsement, recommendation, or favoring by the United States Government or any agency thereof. The views and opinions of authors expressed herein do not necessarily state or reflect those of the United States Government or any agency thereof. 


\section{DISCLAIMER}

Portions of this document may be illegible in electronic image products. Images are produced from the best available original document. 


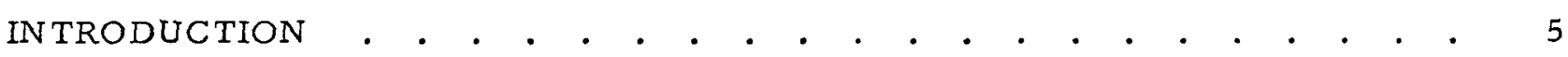
HYDROGEN IN MAGNESIUM SOLUBILITY OF HYDROGEN IN URANIUM SOLUBILITY OF HYDROGEN IN MAGNESIUM FLUORIDE SLAG . . . • . 19 PERMEATION OF MAGNESIUM FLUORIDE SLAG BY HYDROGEN . . . . 21 CALCULATIONS ON DIFFUSION OF HYDROGEN IN URANIUM ROD . . . . 26 REFERENCES . . • • . . . . . . . . . . . . . . . . . . . 32 


\title{
STUDIES RELATING TO HYDROGEN IN DINGOT URANIUM
}

\author{
Max J. Trzeciak and Manley W. Mallett
}

\begin{abstract}
Hydrogen in dingot uranium causes difficulties in further processing and in end use. As a part of the efforts to eliminate this problem, a study was made of the distribution of hydrogen among feed materials and products in the thermite reaction producing dingot uranium.
\end{abstract}

Hydrogen contents of the magnesium used as a feed material in all steps of production were found to be significantly high. The average hydrogen content of magnesium chips used as a feed material is 26 ppm. Redistillation of magnesium can bring the hydrogen levels down to between 8 and 16 ppm. Hydrogen contents can be lowered to about 6 ppm by bubbling chlorine gas through molten magnesium.

The solubility of hydrogen in molten uranium at 1200 and $1300 \mathrm{C}$ was measured at pressures of 5 to $760 \mathrm{~mm}$ of mercury. It was found that, at both these temperatures, the hydrogen solubility varied directly as the square root of the hydrogen pressure over the bath, and at $760 \mathrm{~mm}$ of mercury is $27 \mathrm{ppm}$ at $1200 \mathrm{C}$ and $32 \mathrm{ppm}$ at $1300 \mathrm{C}$.

Measurements of the solubility of hydrogen in molten and solid magnesium fluoride slag at temperatures of 720 to $1350 C$ and at a 1-atm hydrogen pressure showed that magnesium fluoride slag absorbs less than 10 ppm hydrogen. On the other hand, vacuum-fusion analyses of magnesium fluoride slag samples indicated that the hydrogen levels vary from 14 to $41 \mathrm{ppm}$. It is presumed that this hydrogen exists as water or hydroxyl ion.

An experimental technique was proposed and tried for measuring the rate of permeation of hydrogen through molten magnesium fluoride slag. An estimated value of $0.001 \mathrm{~cm}^{3}$ (STP) hydrogen per sec per $\mathrm{cm}^{2}$ slag area through a 1-cm slag depth was tentatively derived from measurements which were shown to have large experimental errors. The sensitivity of this measurement is not satisfactory for the present study.

The possibility of removing hydrogen from uranium by degassing at elevated temperatures and at low pressures was considered. Calculations were made for the diffusion of hydrogen in uranium rod. Several cases were chosen to illustrate the potentialities of this technique.

\section{INTRODUCTION}

The rejection rate of uranium slugs, during canning, for use in reactors is greatly influenced by the hydrogen content of the uranium. (1) Lower hydrogen contents of slugs result in lower rejection rates. One approach to producing low-hydrogen slugs is to limit the hydrogen content of uranium metal as it is formed from uranium tetrafluoride and magnesium in a thermite reactor. As part of this approach, Battelle as sisted Mallinckrodt Chemical Works by undertaking a study of causes of excess hydrogen in dingot uranium.

(1) References at end. 
Hydrogen is carried into the thermite bomb chiefly through the feed materials, magnesium metal chips and uranium tetrafluoride, and through the liner material, magnesium fluoride slag. During the reaction, hydrogen is distributed among the products, and tends to concentrate in dingot uranium metal. The objective of the present study was to obtain a quantitative measurement of the movement and distribution of hydrogen among the various components during the thermite reaction. In this connection, the experimental work covered several phases. The studies on hydrogen contents of magnesium used to reduce uranium tetrafluoride, the solubilities of hydrogen in liquid uranium and in magnesium fluoride slag, the permeation of hydrogen through liquid magnesium fluoride slag, and the diffusion of hydrogen in solid uranium are discussed separately.

\section{HYDROGEN IN MAGNESIUM}

A study of the hydrogen content of the magnesium used in the process was undertaken to determine if the amount of hydrogen being introduced into the thermite reactor from this source could be reduced. Presently, the magnesium chips have hydrogen contents of $26 \mathrm{ppm}$ and have the potential of introducing $5 \mathrm{ppm}$ hydrogen into dingot uranium. The study included an examination of the various magnesium-production steps to determine where hydrogen was being introduced and to determine if production of magnesium chips with hydrogen levels below 5 ppm was feasible. Some laboratory experiments were conducted to determine the effectiveness of bubbling gases through molten magnesium to reduce its hydrogen level.

\section{Sampling of Magnesium}

Samples of magnesium were collected from the various stages in its manufacture and use, as follows:

(1) From New England Lime Company and from Nelco Metals Company, both located in Canaan, Connecticut:

(a) Muff magnesium produced by the Pidgeon process

(b) Fresh magnesium ingot which had just been poured

(c) Magnesium ingot about 3 weeks old (the normal period of storage before shipment)

(d) Redistilled magnesium produced by a process different from the one used by the company in normal production. 
(2) From Metal Sellers Corporation, Putnam, Connecticut:

(a) Normal magnesium ingot as received for processing into chips

(b) Magnesium chips of different sizes taken from each of three steps in the process of making chips from the normal ingot

(c) "Dirty" magnesium ingot with a gray powdery "growth" on one surface

(d) Magnesium chips obtained from the "dirty" ingot

(e) Magnesium ingot which had been stored about 9 months.

(3) From Mallinckrodt Chemical Works, St. Louis, Missouri:

(a) Magnesium chips as received from Metal Sellers Corporation, ready for use in a thermite reactor

(b) Magnesium taken from side wall and top of a thermite reactor.

Analytical Results

Analyses were made according to a method described by Mallett, Gerds, and Griffith(2). The method involves dissolving the sample in a tin bath at $450 \mathrm{C}$ in a vacuum-fusion apparatus. The hydrogen evolved is collected and measured.

Table 1, Part 1, shows that the hydrogen contents of four samples from the same muff ranged from 26 to $165 \mathrm{ppm}$. This wide variation in hydrogen content is considered to be real. From the appearance of this muff and others observed at the plant, this variation in hydrogen content is considered more likely to be typical than unusual. For example, it was noticed at the plant that some muffs had an ammonia odor and others did not. The ammonia appeared to come from the reaction of moisture in the air with magnesium nitride which was present on the surfaces of some muffs. It is not surprising, therefore, that the analytical data indicated a great degree of heterogeneity with respect to hydrogen content.

Nine specimens taken from a freshly poured magnesium ingot showed variations in hydrogen content from 14 to $20 \mathrm{ppm}$. Analyses are listed in Table 1, Part 2. Positions in the ingot from which samples were taken are illustrated in Figure 1. The data show that the concentration of hydrogen on the surface, 16 and $20 \mathrm{ppm}$, is essentially the same as that inside the ingot, $17 \mathrm{ppm}$. It was suspected that surface concentration of hydrogen might be higher because of the reaction of magnesium with moisture from the atmosphere according to the equation, $\mathrm{Mg}+2 \mathrm{H}_{2} \mathrm{O}=\mathrm{Mg}(\mathrm{OH})_{2}+2 \mathrm{H}$. The data show 
TABLE 1. ANALYTICAL RESULTS FOR HYDROGEN IN VARIOUS MAGNESIUM SAMPLES

\begin{tabular}{ccc}
\hline Sample & $\begin{array}{c}\text { Hydrogen(a), } \\
\text { ppm by weight }\end{array}$ & Remarks \\
\hline & Part 1. Muff From New England Lime Company \\
\cline { 2 - 3 } a & 26 & Random sample \\
b & 48 & Ditto \\
c & 78 & Ditto \\
d & 165 & Ditto
\end{tabular}

Part 2. Fresh Magnesium Ingot From New England Lime Company

$\begin{array}{llc}\mathrm{a} & 16 & \text { Surface sample } \\ \mathrm{b} & 20 & \text { Rerun of surface sample } \\ \mathrm{c} & 17 & \text { Gradient study (see Figure 1) } \\ \mathrm{d} & 14 & \text { Ditto } \\ \mathrm{e} & 18 & \text { Ditto } \\ \mathrm{f} & 17 & \text { Ditto } \\ \mathrm{g} & 16 & \text { Ditto } \\ \mathrm{h} & 15 & \text { Ditto } \\ \mathrm{i} & 17 & \text { Ditto }\end{array}$

Part 3. 3-Week-Old Magnesium Ingot From New England Lime Company

$\begin{array}{lll}\text { a } & 24 & \text { Surface sample (see Figure 1) } \\ \text { b } & 31 & \text { Rerun of surface sample (see Figure 1) } \\ \text { c } & 17 & \text { Center sample (see Figure 1) }\end{array}$

Part 4. Redistilled Magnesium Chips From New England Lime Company

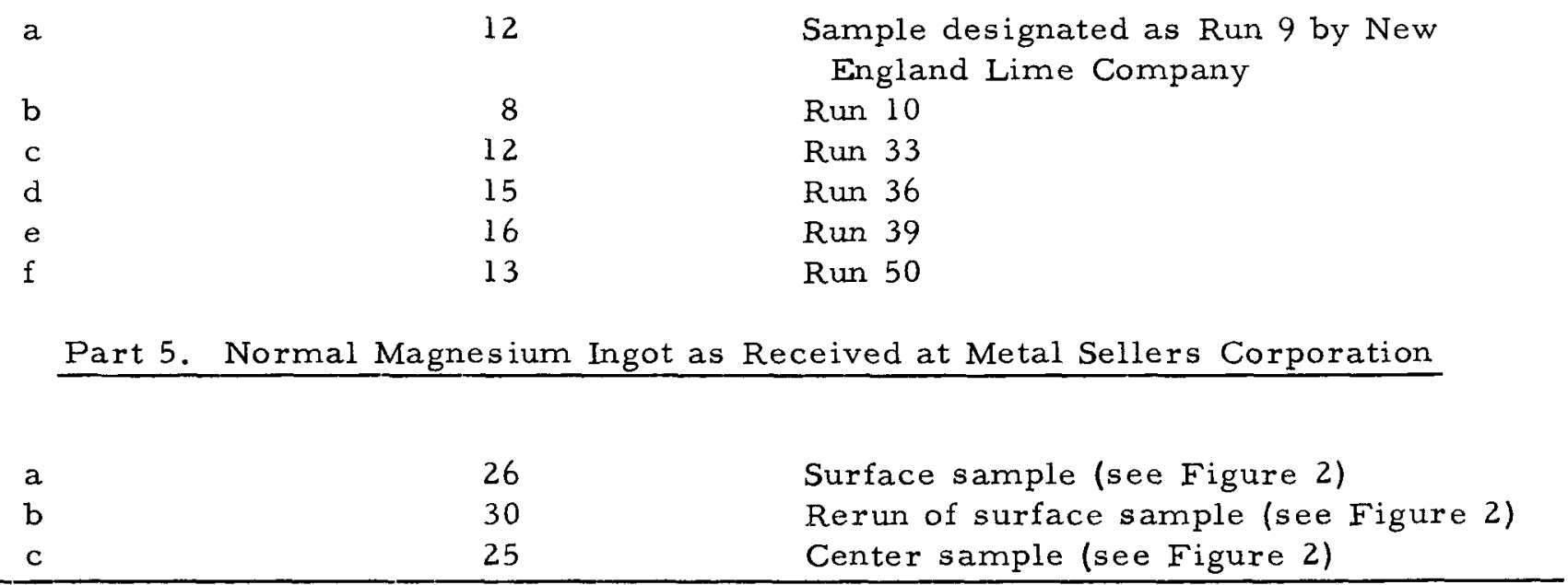


TABLE 1. (Continued)

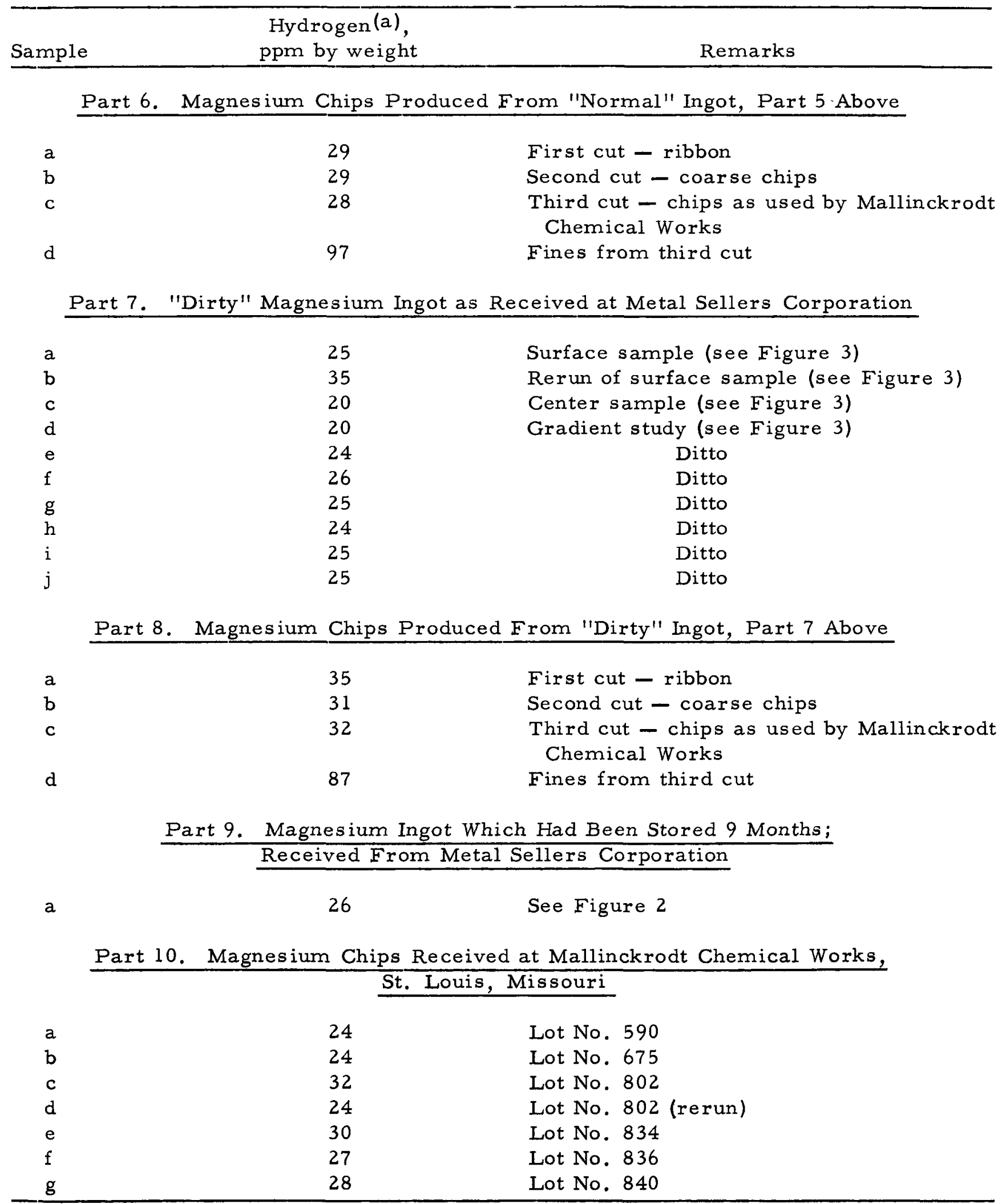


TABLE 1. (Continued)

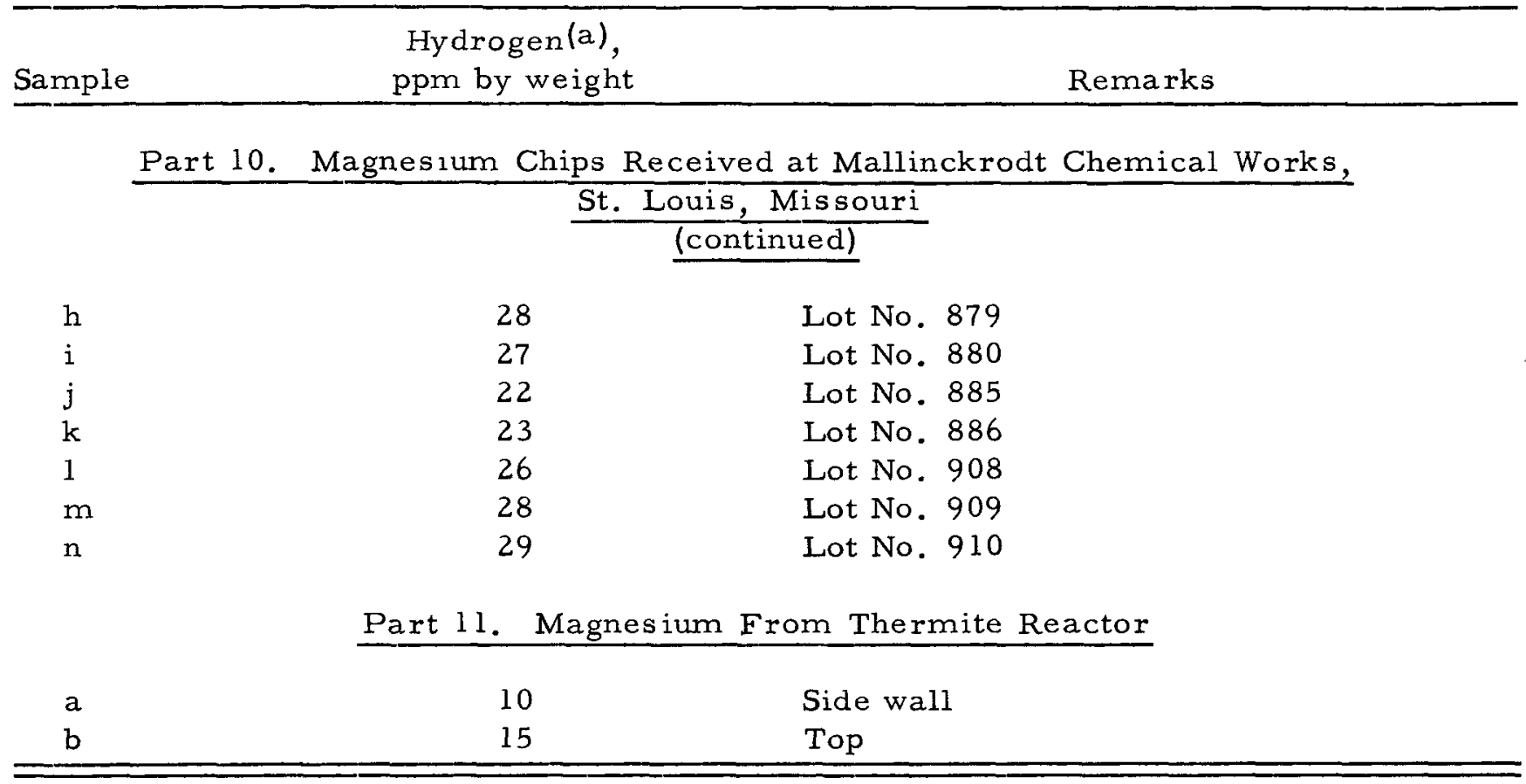

(a) The sensitivity of the apparatus in which these analytical measurements were made is equivalent to \pm 0.6 ppm hydrogen for the $1.5 \mathrm{-g}$ samples used and varies inversely with the sample weight. It is general experience, however, that the values obtaned for a multiplicate series of vacuum-fusion analyses agree to about 10 relative per cent. Of course, as in all analytical work, random errors greater than this occasionally occur. 


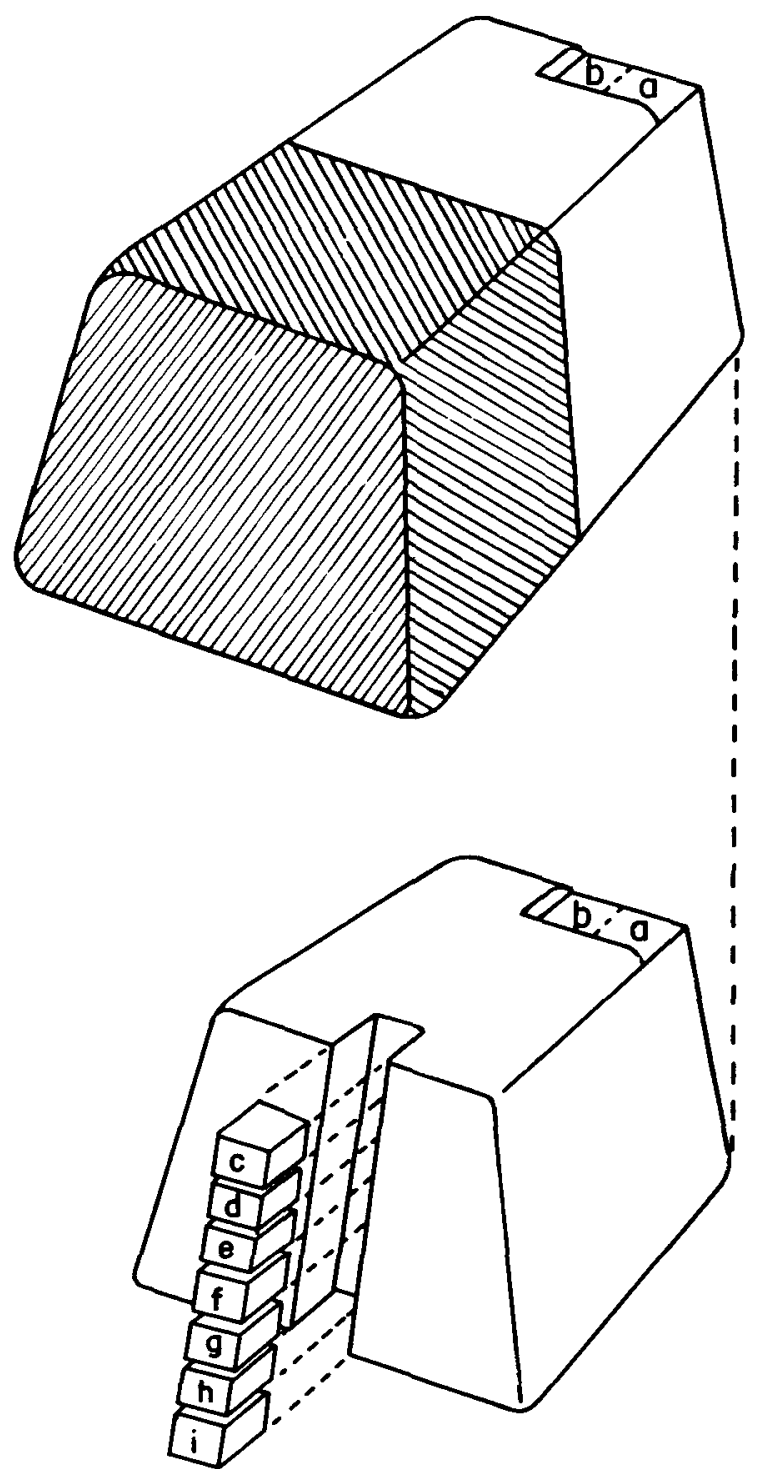

Fresh Magnesium Ingot (Table 1, Part 2)

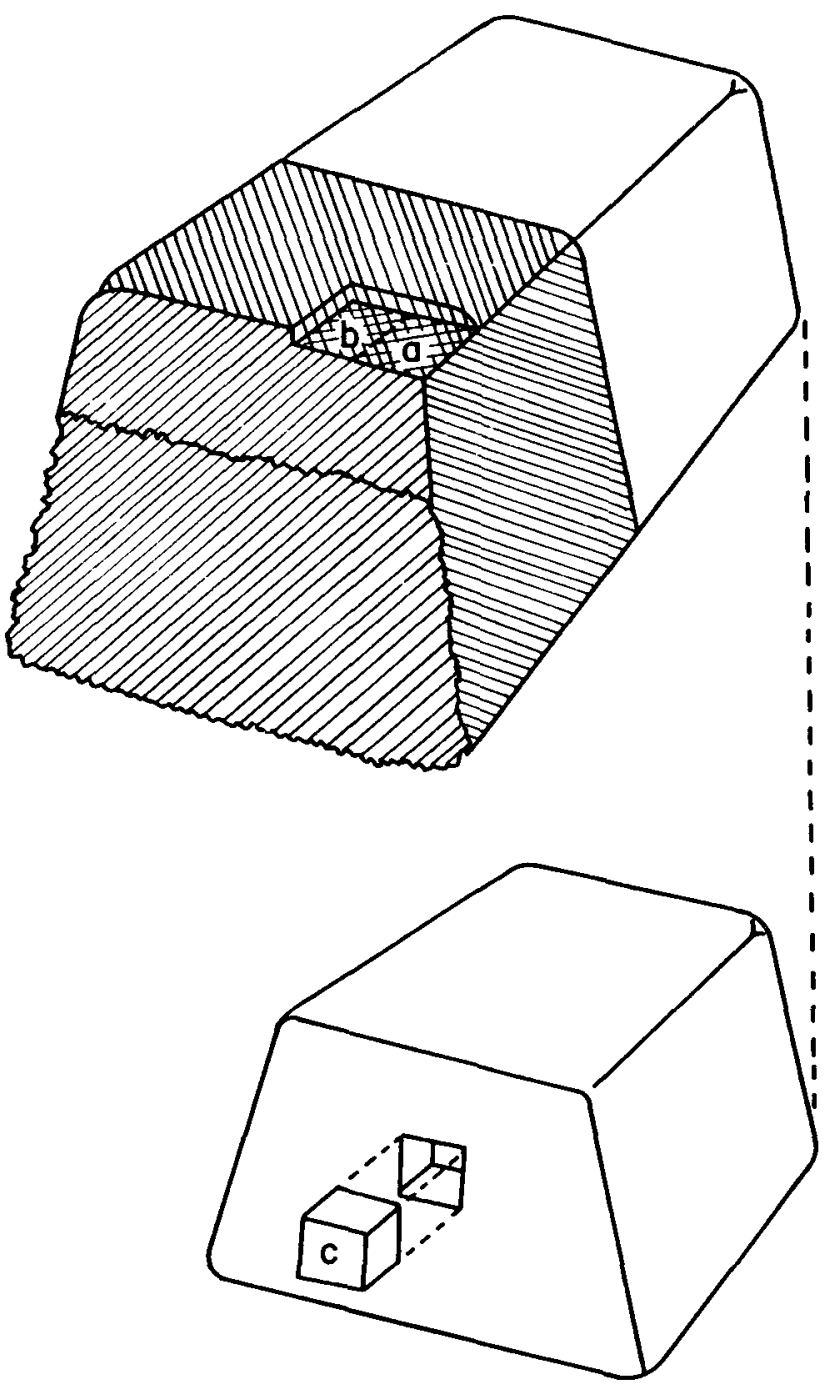

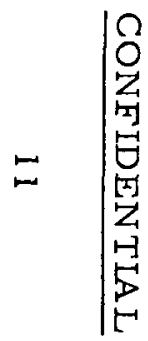

3-Week-Old Magnesium Ingot (Toble I, Part 3 )

FIGURE 1. LOCATION OF SAMPLES TAKEN FROM MAGNESIUM INGOTS FROM NEW ENGLAND LIME COMPANY 
$\therefore: .:$

$\vdots \ldots . .:$

.....

…:

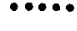

$\because \because$

$\because \because$

$\because \because$

$\vdots \ldots$

$\therefore$

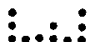

$\therefore . . .:$

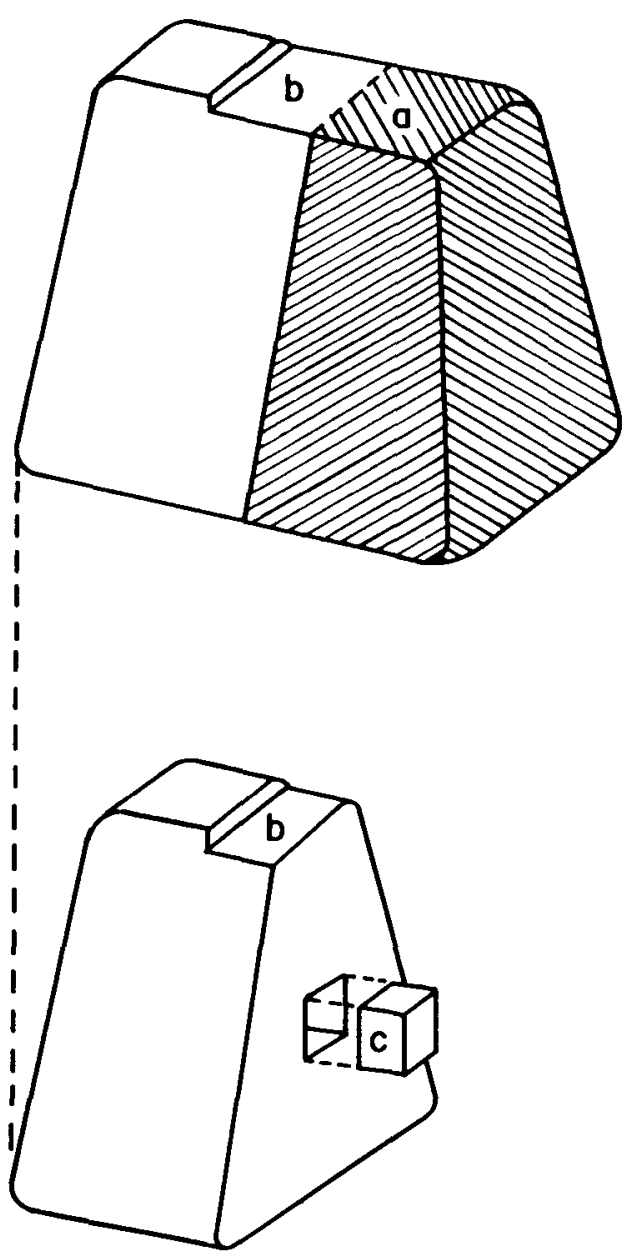

Normal Mognesium Ingof (Table 1, Part 5)

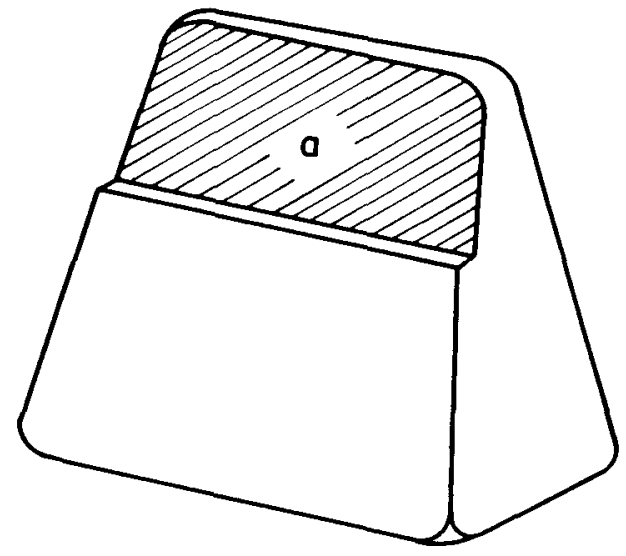

Magnesium Ingot Which Had Been Stored 9 Months (Table I, Part 9)

FIGURE 2. LOCATION OF SAMPLES TAKEN FROM MAGNESIUM INGOTS FROM METAL SELLERS CORPORATION 

that if this reaction does occur, the free hydrogen formed is not necessarily concentrated near the surface. In addition, a gradient study of this ingot was made. Results show that this ingot is relatively homogeneous, with a hydrogen content of $16 \pm 2 \mathrm{ppm}$ (see Figure 1 and Table 1, Part 2, Samples c, d, e, f, g, h, and i).

Data in Table 1, Part 3, for the 3-week-old magnesium ingot from the New England Lime Company show that hydrogen levels are higher but not significantly different in this study from those of the freshly poured ingot. The average of three samples taken from this ingot is $24 \mathrm{ppm}$.

The average hydrogen content, $13 \mathrm{ppm}$, of the redistilled magnesium, Table 1 , Part 4, indicates that the hydrogen level is lower than that of the normal production magnesium.

Analytical results for a normal ingot as received at Metal Sellers Corporation show that hydrogen levels are about the same as those for ingots being shipped from the New England Lime Company. Hydrogen levels listed in Table 1, Part 5, average 27 ppm. An investigation of the change in hydrogen content upon chipping indicated that this operation has little or no effect. This is shown by the analyses of Samples a, b, and $c$ in Table 1, Part 6. These results are close to the base hydrogen level of the initial ingot, Table l, Part 5. Fines removed from the product of the final chipping operation contained $97 \mathrm{ppm}$ hydrogen. No conclusive explanation for this high hydrogen level is evident. It is possible that contamination from handling fines at Metal Sellers Corporation may account for the excess hydrogen. Also, the larger surface area of fines may have some bearing on the elevated hydrogen level, but this is not borne out by a comparison of results of analyses between the ingot and the chips, especially Sample c, Table 1, Part 6. Since fines are not used but discarded, this result has minor significance in this study.

Personnel at Metal Sellers Corporation stated that about 5 to 10 per cent of the ingots are received with partly contaminated surfaces. The contamination consists of a gray powdery "growth" on the surface. It was decided to determine whether this contamination affected hydrogen levels in the final chips. Therefore, an ingot, termed "dirty", was processed in the same manner as that for the normal ingot described above. Analytical results showed that the ingot had an average original hydrogen content of $25 \mathrm{ppm}$ (Samples a through $\mathrm{j}$ in Table 1, Part 7). Also, a gradient study, Samples $d$ through $j$ in Table 1 , Part 7 , showed the ingot to be relatively homogeneous with respect to hydrogen. The chipping operation gave chips with hydrogen levels averaging 33 ppm (Samples a, b, and $c$ in Table 1, Part 8). As in the case of the normal ingot, the fines were found to contain an excessive amount of hydrogen, $87 \mathrm{ppm}$ (Sample d in Table 1, Part 8). From these results, it is concluded that "dirt" in the ingots does not greatly affect the hydrogen content of the magnesium.

An ingot which had been stored 9 months was obtained from Metal Sellers Corporation for analys is to determine the effect of age on the hydrogen content of magnesium ingots. An analysis of this ingot, Sample a in Table 1, Part 9, shows that the hydrogen content, $26 \mathrm{ppm}$, is essentially the same as that of the relatively fresh ingots. Therefore, it is concluded that aging has no apparent effect upon hydrogen content of ingots. 
The hydrogen contents of 13 lots of magnesium chips, Table 1, Part 10, received at Mallinckrodt Chemical Works only varied from 22 to $32 \mathrm{ppm}$. The average level, $26 \mathrm{ppm}$, was the same as that of the finished product manufactured by Metal Sellers Corporation. This shows that there was no hydrogen pickup during shipment.

Magnesium taken from the side wall and the top of a thermite reactor following reaction contained 10 and $15 \mathrm{ppm}$ hydrogen, respectively, as indicated by Samples a and b in Table 1, Part 1 .

Experiments to Reduce Hydrogen Levels in Magnesıum

The above survey shows that the hydrogen content of magnesium muffs is high. The hydrogen level is reduced somewhat during melting and casting and then is not greatly changed in the chipping process. Therefore, it appears that lowering of the hydrogen content at the melting step would lead to a more satisfactory final product.

An investigation was made to determine if hydrogen could be removed easily during melting. Two experiments were made in which chlorine and dry helium gases were bubbled through molten magnesium.

In the first experiment, a $20-1 b$ melt at $1450 \mathrm{~F}(790 \mathrm{C})$ was saturated with hydrogen by flushing with steam. Then chlorine was bubbled through the melt. The depth of the melt, contained in a steel crucible, was $10 \mathrm{in}$. The chlorine was introduced near the bottom of the melt. The rate of gas flow was not recorded. However, the gas flow was such as to cause a gentle rocking motion in the melt without violent bubbling. Samples were removed for hydrogen analysis after the melt had been purged with chlorine for various lengths of time. Results of hydrogen analyses follow.

\begin{tabular}{cc} 
Sample & Hydrogen, ppm \\
\cline { 1 - 2 } 1 & 21 \\
2 & 19 \\
3 & 11 \\
4 & 6 \\
5 & 7 \\
6 & 7
\end{tabular}

After steam flush

After 20 -min purging with chlorine After 40-min purging with chlorine A fter 60-min purging with chlorine After 80-min purging with chlorine After $100-\mathrm{min}$ purging with chlorine

The sensitivity of these measurements $1 \mathrm{~s} \pm 0.5 \mathrm{ppm}$. These results show that an equilibrium hydrogen level of about 6 ppm is reached after a 60-min purging. This hydrogen level probably can be attributed to moisture in the chlorine gas used.

For the second experiment, no steam flush was used and helium was dried by passing through a copper coll submerged in a liquid-nitrogen trap. The dried helium then was bubbled through a magnesium melt similar to the technique described above for chlorine. Samples were taken from time to time and analyzed for hydrogen. Results of the analyses follow. 


\begin{tabular}{lc} 
Sample & Hydrogen, \\
\cline { 2 - 2 } 1A & 10 \\
1B & 4 \\
2 & 5 \\
3 & 3 \\
4 & 5 \\
5 & 4 \\
6 & 4 \\
7 & 5 \\
8 & 7
\end{tabular}

Identification
Charge material
After meltdown
After $30-$ min purging with helium
After $60-$ min purging with helium
After $90-$ min purging with helium
After $120-$ min purging with helium
After $150-$ min purging with helium
After $180-$ min purging with helium
After $240-$ min purging with helium

The sensitivity of these measurements is $\pm 0.5 \mathrm{ppm}$. The results show that the hydrogen level dropped from $10 \mathrm{ppm}$ in the charge material to $4 \mathrm{ppm}$ after meltdown. It is possible that the charge material was not homogeneous with respect to hydrogen, giving a different analysis when melted. However, for aluminum, merely melting and refreezing will get rid of most of the hydrogen. Maybe this occurs in magnesium also. No extended study of this was made. The results of the purge indicate that an equilibrium level of about $5 \mathrm{ppm}$ is maintained with dry helium.

\section{Conclusions}

The analytical results show that hydrogen is present $i$ significant concentrations in magnesium from the initial production material to the final product used in the thermite reactor. The hydrogen content of muffs can be reduced by redistilling or melting. Hydrogen levels of 26 to $165 \mathrm{ppm}$ in muffs are reduced to 8 to $16 \mathrm{ppm}$ by redistilling. Melting of muffs yields metal containing 14 to $35 \mathrm{~F}, \mathrm{~m}$ hydrogen.

Further reduction in hydrogen content can be achieved by bubbling chlorine gas through magnesium melts. The lowest hydrogen level obtained by this technique was about 6 ppm.

\section{SOLUBILITY OF HYDROGEN IN URANIUM}

A study was made of the solubility of hydrogen in molten uranium and its pressure dependency. The objective was to determine if the solubility varied directly as the square root of hydrogen pressure over molten uranium. A knowledge of these solubility data enables one to check the reasonableness of proposed hypotheses explaining the movement of hydrogen among the various components of the thermite reactor immediately following reaction.

For this study, three temperatures, 1200, 1300, and $1450 \mathrm{C}$, were selected. The hydrogen-pressure range of interest extended from about 5 to $760 \mathrm{~mm}$ of mercury. In addition, it was desired to determine the rate at which equilibrium was established. 
Experimental Work

For each of the runs made, solubilities were measured as follows. Uranium was placed in a modified Sieverts apparatus(3) and degassed at $850 \mathrm{C}$. Hydrogen then was added in small increments, equilibrium being established before each successive addition. Equilibrium was considered established at a given constant temperature when no pressure change was observed for $5 \mathrm{~min}$. This procedure was repeated until sufficient hydrogen was added to give a 1 -atm pressure. Three runs were made at temperatures of 1200,1300 , and $1450 \mathrm{C}$.

Solubilities at equilibrium pressures from 3 to $760 \mathrm{~mm}$ of mercury were obtained for a $149-\mathrm{g}$ sample at $1200 \mathrm{C}$ in a $3.0-\mathrm{cm}$-diameter quartz crucible. The surface-tomass ratio in this case is $0.015 \mathrm{~cm}^{2}$ per $\mathrm{g}$. Data for this run are listed below.

\begin{tabular}{ccc}
$\begin{array}{c}\text { Hydrogen Pressure, } \\
\text { mm of mercury }\end{array}$ & $\begin{array}{r}\text { Hydrogen Sorbed, } \\
\text { ppm }\end{array}$ & $\begin{array}{c}\text { Equilibrium Time, } \\
\text { min }\end{array}$ \\
\cline { 2 - 3 } 16 & 1.6 & -- \\
53 & 4.4 & 20 \\
154 & 7.7 & 20 \\
276 & 13.3 & 21 \\
760 & 17.0 & 28 \\
& 27.1 & 26
\end{tabular}

The data show that equilibrium is readily established within $1 / 2 \mathrm{hr}$ for the various hydrogen levels. In addition, a plot of these data, Figure 4, shows that the solubility varies as the square root of hydrogen pressure. The solubility varies from $1.6 \mathrm{ppm}$ at a $3-\mathrm{mm}$ hydrogen pressure to $27.1 \mathrm{ppm}$ at a $760-\mathrm{mm}$ hydrogen pressure.

Equilibrium pressures of 7 to $756 \mathrm{~mm}$ of mercury were used in determining solubilities at $1300 \mathrm{C}$ using a $142-\mathrm{g}$ sample in the $3.0-\mathrm{cm}$-diameter quartz crucible. The surface-to-mass ratio is $0.016 \mathrm{~cm}^{2}$ per $g$ for this case. These data follow:

\begin{tabular}{cc}
$\begin{array}{c}\text { Hydrogen Pressure, } \\
\text { mm of mercury }\end{array}$ & $\begin{array}{c}\text { Hydrogen Sorbed, } \\
\text { ppm }\end{array}$ \\
\cline { 2 - 2 } 7 & 3.9 \\
23 & 5.3 \\
47 & 7.4 \\
283 & 18.2 \\
756 & 32.2
\end{tabular}

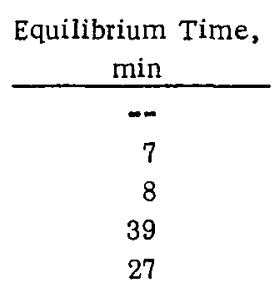

The $1300 \mathrm{C}$ data show that the time required for reaching equilibrium ranges from 7 to $39 \mathrm{~min}$, being higher at elevated pressures where solubility is greater. However, no direct relationship between the time required to reach equilibrium and either pressure or solubility is evident. Again, the solubility varies as the square root of pressure, as seen in Figure 4.

Another run was made at $1450 \mathrm{C}$ with measurements at hydrogen pressures of 214 to $558 \mathrm{~mm}$ of mercury. During the experiment, it was noted that the uranium was reacting with the quartz crucible at a comparatively rapid rate. At the conclusion of the experiment the uranium sample was removed and weighed to determine the extent 


\section{CONFIDENTIAL}

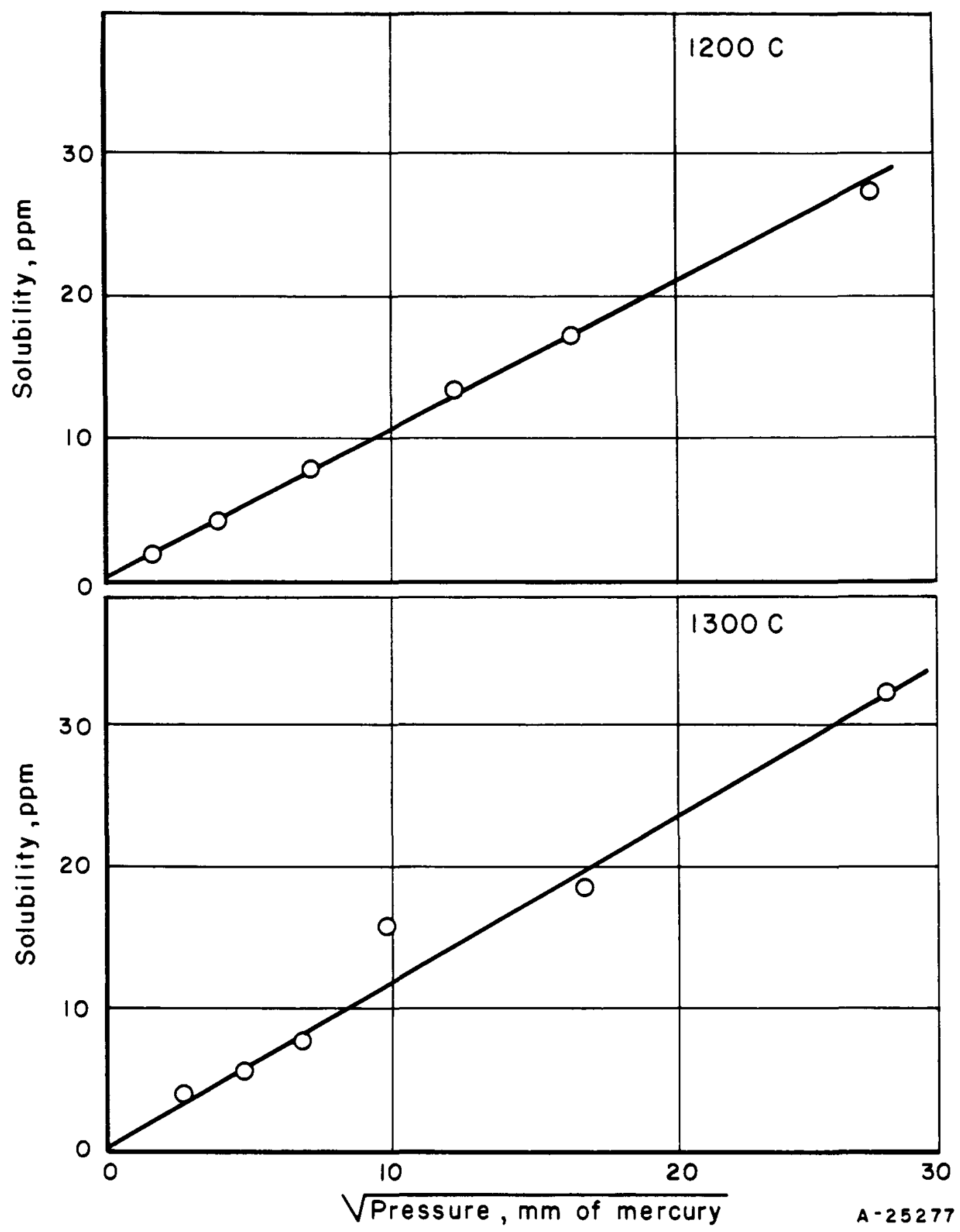

FIGURE 4. VARIA TION OF SOLUBILITY OF HYDROGEN IN URANIUM WITH SQUARE ROOT OF HYDROGEN PRESSURE 
of reaction. It was found that about $20 \mathrm{w} / \mathrm{o}$ of the uranium had been consumed by reaction with quartz. As a result of this observation it was concluded that the data at $1450 \mathrm{C}$ are not reliable. On the other hand, the extent of reaction between uranium and quartz at 1200 and $1300 \mathrm{C}$ amounted to about $1 / 2 \mathrm{w} / \mathrm{o}$, a negligible amount in this study.

The data obtained in this study at a l-atm pressure and at 1200 and $1300 \mathrm{C}$ agree well with those obtained by extrapolating older Battelle data. (4) A comparison of the two sets of data is given in the following tabulation.

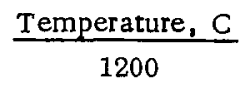

1300

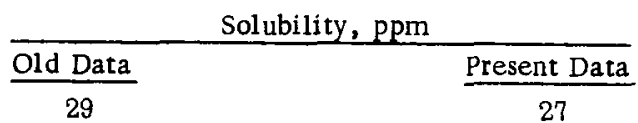

31

32

The uncertainty in the present data is about $1.5 \mathrm{ppm}$. In view of this and an estimated uncertainty of $1.5 \mathrm{ppm}$ in the published data, it is seen that rather close agreement has been obtained.

\section{Discussion}

The experiments at 1200 and $1300 \mathrm{C}$ indicate that the solubility varies with the square root of hydrogen pressure. With this information, and with an equation for solubility of hydrogen in molten uranium derived from previous work at Battelle(5),

$$
\log \frac{\mathrm{S}}{\sqrt{\mathrm{p}}}=-\frac{587}{\mathrm{~T}}+0.426 \text {, }
$$

it is possible to estimate solubilities over a wide range of temperatures and pressures.

\section{SOLUBILITY OF HYDROGEN IN MAGNESIUM FLUORIDE SLAG}

Hydrogen is introduced into the thermite reactor principally by way of the feed materials, magnesium and uranium hexafluoride. The liner material, powdered magnesium fluoride slag, is also a possible source of hydrogen. Part of the problem is to determine how the hydrogen from these sources is distributed after reaction takes place. Therefore, a study was made of the solubility of hydrogen in molten and solid magnesium fluoride slag. In this way, it is possible to estimate the amount of hydrogen retained in the slag following reaction.

The study consisted of two phases. One was concerned with measurement of hydrogen gas absorbed by degassed samples of slag. The other consisted of the analytical measurement of hydrogen extracted from samples of production slag. 
Measurement of Hydrogen Gas Absorbed by Slag

Experimental measurements were made with the modified Sieverts apparatus described in the preceding section for hydrogen solubility in liquid uranium. Graphite or molybdenum crucibles were used in high-temperature runs. Heating was accomplished by induction and the crucibles acted as susceptors to heat the magnesium fluoride slag. In addition, a quartz crucible heated by a resistance furnace was used in one run at $720 \mathrm{C}$.

In a typical run, about $25 \mathrm{~g}$ of magnesium fluoride slag (melting point, $1250 \mathrm{C}$ ) was placed in a crucible and outgassed at $1300 \mathrm{C}$. The slag was furnished by Mallinckrodt Chemical Works from one of the production runs. A calibration of the volume of the system was then made at the experimental temperature with helium at atmospheric pressure. Next, hydrogen was added intermittently to maintain atmospheric pressure and when absorption stopped the cumulative hydrogen addition was determined. Another calibration with helium was then made. The difference between the amount of hydrogen added and the volume calibration with helium was taken as the amount of hydrogen absorbed by magnesium fluoride slag.

Measurements at $720,820,920,1020,1150,1260$, and $1350 \mathrm{C}$ at a 1 -atm hydrogen pressure on different samples of slag showed that no hydrogen was absorbed within the sensitivity limits of the measurements. The sensitivity limit is estimated at 10 ppm hydrogen.

In the course of making some of the experimental measurements it was noted that hydrogen was absorbed by the slag upon cooling to room temperature. The amounts of hydrogen ranged from 6 to $187 \mathrm{ppm}$, as the following tabulation shows:

\begin{tabular}{cc} 
Run & $\begin{array}{c}\text { Hydrogen Sorption Upon Cooling } \\
\text { to Room Temperature, } \\
\text { ppm by werght }\end{array}$ \\
\hline 1 & 142 \\
2 & 28 \\
3 & 45 \\
4 & 24 \\
5 & 187 \\
6 & 6
\end{tabular}

Equilibrium. pressure measurements made at different temperatures on one of the slag samples correspond with those for pure uranium hydride. Consequently, it appears that the hydrogen was absorbed by uranium, which is an impurity in the slag. Since a different sample was used for each run, it appears that the variation in hydrogen absorbed is a function of the inhomogeneity in uranium content of the slag. 
Analytical Measurement of Hydrogen Extracted From Samples of Production Slag

The following tabulation gives results of analyses of hydrogen contents of slag samples received from the Mallinckrodt Chemical Works.

\begin{tabular}{|c|c|c|c|}
\hline Sample & Weight, $g$ & $\begin{array}{c}\text { Hydrogen, } \\
\text { ppm by weight }\end{array}$ & Remarks \\
\hline $1 \mathrm{~A}$ & 3.05 & 40 & Dingot liner slag, powdered \\
\hline $1 \mathrm{~B}$ & 2.10 & 41 & Rerun \\
\hline $2 \mathrm{~A}$ & 3.05 & 36 & $\begin{array}{l}\text { Ground slag, Sample 2; pro- } \\
\text { duction bomb-liner slag, } \\
\text { powdered }\end{array}$ \\
\hline $2 \mathrm{~B}$ & 2.45 & 32 & Rerun \\
\hline $3 \mathrm{~A}$ & 4.47 & 14 & $\begin{array}{l}\text { Fused slag taken directly from } \\
\text { a frred bomb }\end{array}$ \\
\hline
\end{tabular}

Hydrogen was extracted from the molten slag at $1300 \mathrm{C}$ in a graphite crucible. The samples were wrapped in tin foil and placed in a storage arm of a vacuum-fusion apparatus prior to dropping into a graphite crucible. Each sample was dropped into the crucible initially at $1000 \mathrm{C}$. Temperature was held at $1000 \mathrm{C}$ for $10 \mathrm{~min}$ and then raised to $1200 \mathrm{C}$ where it was held for another $10 \mathrm{~min}$. Then the temperature was raised to $1300 \mathrm{C}$ and extraction carried out to blank rate. Results showed that extraction at $1000 \mathrm{C}$ was slow. At $1200 \mathrm{C}$ the rate of gas evolution was substantially higher, while at $1300 \mathrm{C}$ it was quite rapid. Complete extraction was effected about $\mathrm{l}$ hr after the sample was dropped into the crucible. Analyses of gases evolved from the slag showed a substantial amount of oxygen present in the slag. However, no reliable, reproducible figure was obtained for oxygen.

\section{Discussion}

The results above show that, within the sensitivity limits of experimental measurements, less than $10 \mathrm{ppm}$ of hydrogen gas is absorbed by both solid and molten magnesium fluoride slag at 720 to $1350 \mathrm{C}$ at a 1 -atm pressure of hydrogen. On the other hand, analytical measurements show that from 14 to $41 \mathrm{ppm}$ of hydrogen can be extracted from molten slag. It is presumed that this hydrogen is bound, probably as water or hydroxyl ion.

\section{PERMEATION OF MAGNESIUM FLUORIDE SLAG BY HYDROGEN}

After reaction occurs in the thermite reactor, the uranium metal produced flows to the bottom of the reactor because of its great density. The less dense magnesium fluoride slag in the liquid state collects above the liquid uranium. As liquid uranium cools, its hydrogen solubility decreases. As a result, the excess hydrogen is ejected. 
Upon being ejected, the hydrogen rises to the top of the uranium and is trapped by a molten plug of magnesium fluoride slag. It then permeates this plug and occupies space above the molten slag. The purpose of this study was to determine how rapidly hydrogen permeates molten magnesium fluoride slag. In addition, it was desired to measure qualitatively the permeation of solid magnesium fluoride slag by hydrogen. This results from the observation that magnesium fluoride slag solidifies first at about $1250 \mathrm{C}$. Then uranium solidifies at its melting temperature of $1130 \mathrm{C}$. In the range 1250 to $1130 \mathrm{C}$, hydrogen is permeating solid slag.

$\underline{\text { Experimental Procedure and Results }}$

The technique for determining permeability involved measuring the rate of hydrogen absorption by a piece of zirconium suspended in the center of a mass of molten magnesium fluoride slag. In effect, the zirconium acted as a sink for hydrogen. Hydrogen pressure was maintained constant around the slag at 1 atm. This was accomplished by displacing hydrogen with mercury in a part of the system remote from where permeation through slag was taking place. This displacement is a measure of hydrogen absorption by zirconium inside the slag.

Prior to the experimental measurement of the rate of permeation, two runs were made to determine the amount and the rate of hydrogen pickup by zirconium. These experiments indicated that about $30 \mathrm{~cm}^{3}$ (STP) of hydrogen is absorbed per $\mathrm{g}$ of zirconium in $30 \mathrm{~min}$ at $1300 \mathrm{C}$ under a l-atm hydrogen pressure.

An experimental measurement was made as follows: A cylinder of zirconium was submerged in magnesium fluoride slag, supported by means of a molybdenum setter. The system, consisting of zirconium, slag, and setter, was contained in a molybdenum crucible heated by induction. The setup is illustrated in Figure 5 . The system was held at a constant temperature of $1300 \pm 10 \mathrm{C}$ for $5 \mathrm{hr}$. In this time a $4.8-\mathrm{g}$ sample of zirconium inside molten slag absorbed $96 \mathrm{~cm}^{3}$ (STP) hydrogen. The rate of hydrogen absorption was constant for the first $220 \mathrm{~min}$. This is evident from the straight-line relationship of hydrogen absorbed plotted against time, as shown in Figure 6 . The lowe $x$ rate of absorption after about 220 min appears to be a result of a decrease in the effective hydrogen pressure over the zirconium. This comes about because the hydrogen concentration in zirconium has increased to where the dis sociation pressure of hydrogen in zirconium is significant compared with the external hydrogen pressure of $1 \mathrm{~atm}$. This experiment gave an estimated tentative value of $0.002 \mathrm{~cm}^{3}$ (STP) hydrogen per sec per $\mathrm{cm}^{2}$ slag area through $1 \mathrm{~cm}$ of slag depth for the permeation of hydrogen at a l-atm pressure through molten slag. This value was derived in the following manner: The amount of hydrogen absorbed by zirconium in 220 min was 75 $\mathrm{cm}^{3}$ (STP). It was assumed that hydrogen permeated only the slag in the open end of the cylindrical molybdenum crucible. In such a case, it is assumed that molybdenum acts as a barrier to hydrogen permeation. The surface area of the slag in the open end of the molybdenum crucible was calculated as $3 \mathrm{~cm}^{2}$ from the dimensions given in Figure 5. The height of slag through which hydrogen diffused was $1.1 \mathrm{~cm}$. From these data, the value reported above was calculated. 


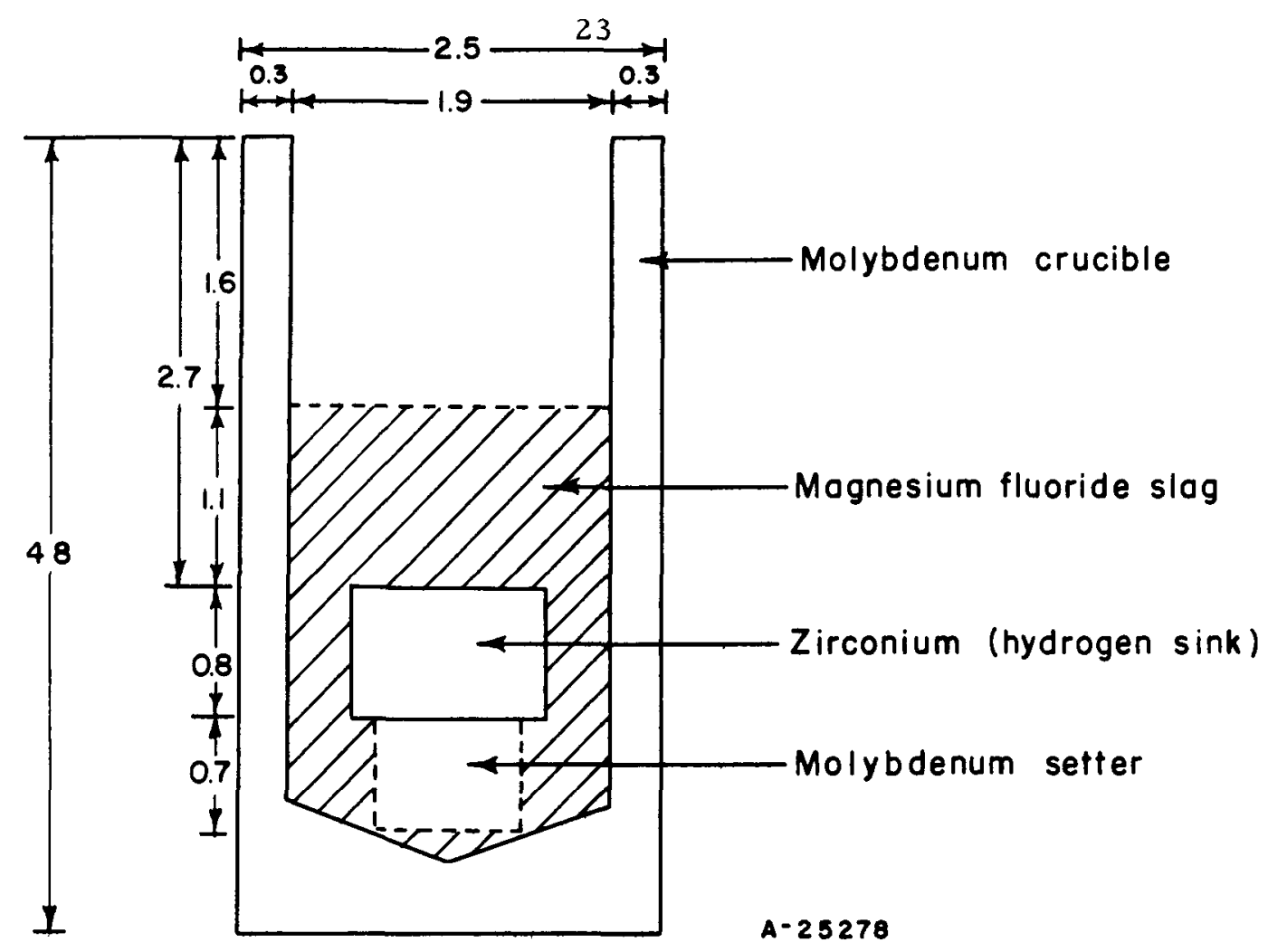

\section{FIGURE 5. EXPERIMENTAL SYSTEM FOR MEASURING PERMEATION OF HYDROGEN THROUGH MAGNESIUM FLUORIDE SLAG}

Scale: $2 \mathrm{X}$.

Units: Centimeters.

A second experimental measurement was made by a method similar to the one above. A value of $0.0006 \mathrm{~cm}^{3}$ (STP) hydrogen per sec per $\mathrm{cm}^{2} \mathrm{slag}$ area through $1 \mathrm{~cm}$ of slag depth was obtained. Both runs appeared to be valid. However, there is a threefold difference between the permeation values obtained. Therefore, a close examination of the technique was made.

It was found that during the experiments the zirconium samples lost substantial portions of their original weights (up to 50 per cent). This indicated that reaction was occurring between zirconium and some component of the slag. A metallographic examination of a zirconium specimen taken after a run, Figure 7, showed that zirconium was dissolving a large amount of some component of the slag, probably oxygen. Previous vacuum-fusion analyses had revealed that the slag contained, in addition to the 14 to $41 \mathrm{ppm}$ hydrogen reported in the tabulation on page 21 , about $250 \mathrm{ppm}$ oxygen and $1000 \mathrm{ppm}$ nitrogen. Therefore, it seemed reasonable that either oxygen or nitrogen, or both were reacting with zirconium. In addition, it appeared that reaction was possible between free magnesium in the slag and zirconium. Therefore, analyses were made for oxygen, nitrogen, and magnesium. Reaction between zirconium and magnesium fluoride was not considered likely on the basis of free-energy calculations. 


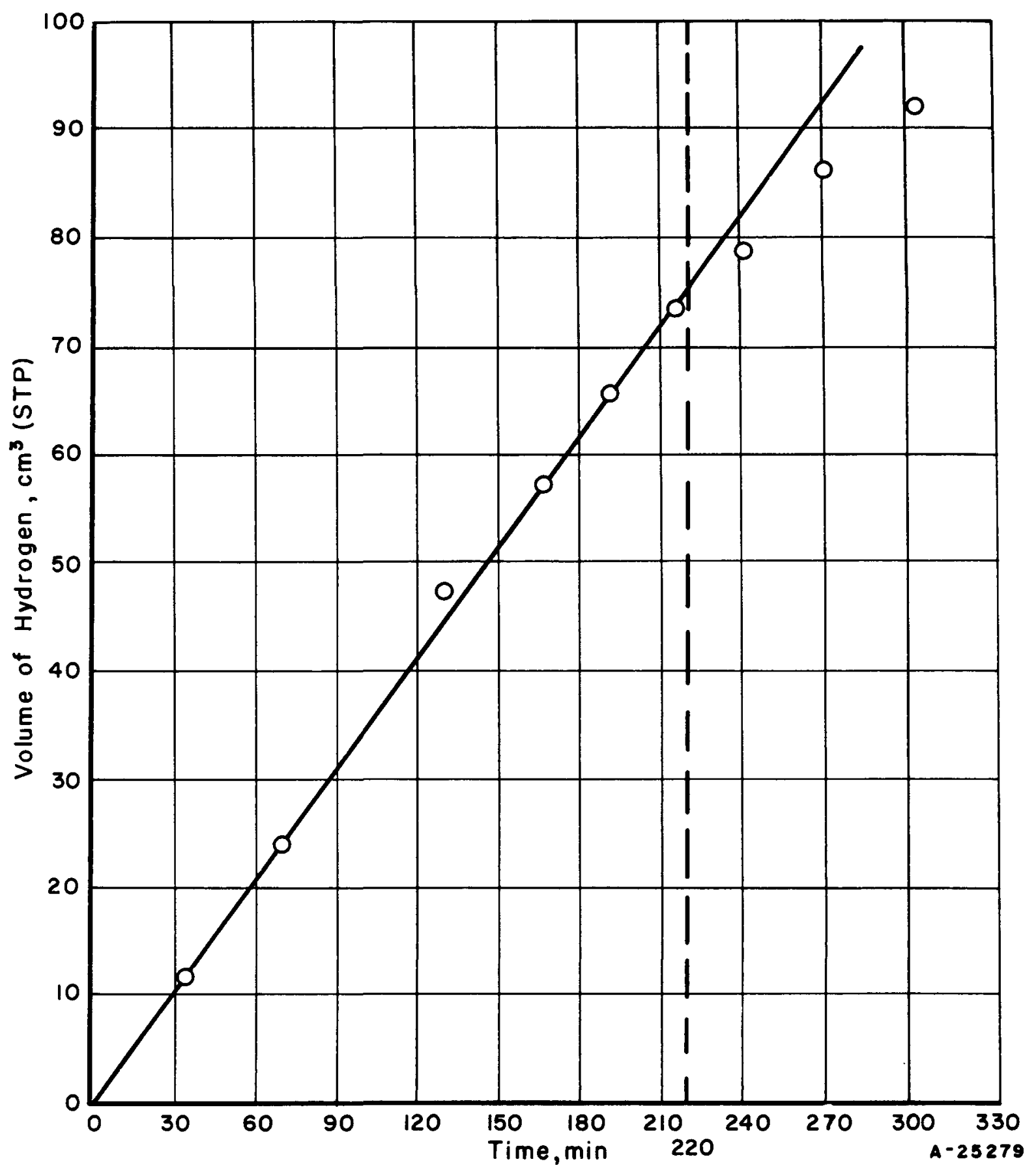

FIGURE 6. PERMEATION OF HYDROGEN THROUGH MOLTEN MAGNESIUM FLUORIDE SLAG 


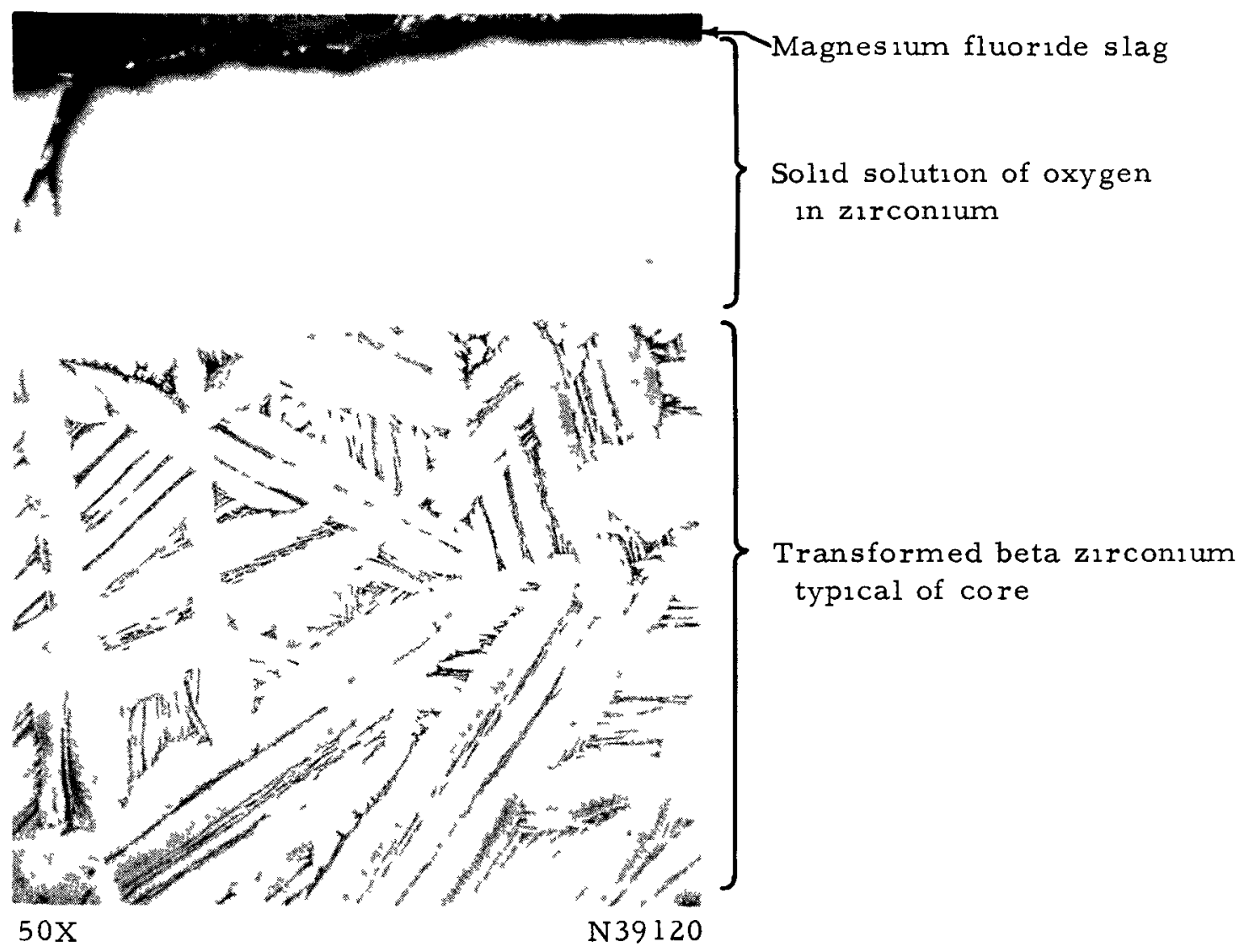

FIGURE 7. PHOTOMICROGRAPH OF ZIRCONIUM SPECIMEN SHOWING REACTION WITH OXYGEN FROM MAGNESIUM FLUORIDE SLAG 
The results of analyses follow.

\begin{tabular}{llcl} 
Element & $\begin{array}{c}\text { Sample } \\
\text { Location }\end{array}$ & $\frac{\text { Analysis, w/o }}{3.8}$ & \multicolumn{1}{c}{$\begin{array}{c}\text { Analytical } \\
\text { Technique }\end{array}$} \\
\cline { 3 - 5 } Oxygen & Surface & 1.2 & Vacuum fusion \\
Core & Surface & 0.004 & Vacuum fusion \\
Nitrogen & Surface & Between 0.05 & Kjeldahl \\
and 0.005 & Spectrographic
\end{tabular}

The $3.8 \mathrm{w} / \mathrm{o}$ oxygen on the surface and the $1.2 \mathrm{w} / \mathrm{o}$ oxygen in the core show that substantial reaction took place between the zirconium and oxygen from the slag. Nitrogen and magnesium contents were not excessive.

These results point to the necessity of considering the effect of oxygen on the reaction of hydrogen with zirconium. It is possible that the zirconium-oxygen surface layer may deter the flow of hydrogen into the zirconium core; that is, the permeation of hydrogen through molten slag may be very rapid, but permeation through the zirconium-oxygen layer is slow. In such a case, permeation through the zirconiumoxygen layer would be the rate-controlling step and the values reported above would not be valid.

In view of these results with impure magnesium fluoride slag the compatibility of zirconium with chemically pure magnesium fluoride was tested at $1300 \mathrm{C}$ under argon. The result was similar to that obtained using the slag. A sizable reaction zone is evident in the photomicrograph, Figure 8 , of the cross section of the surface layer of the zirconium specimen.

\section{Discussion}

On the basis of the above discussion it appears that the experimental technique used is not satisfactory in this study for accurately measuring the permeability of magnesium fluoride slag to hydrogen. However, a permeation value consisting of the average of the two experimental values, $0.001 \mathrm{~cm}^{3}$ (STP) hydrogen per sec per $\mathrm{cm}^{2}$ slag area through $1 \mathrm{~cm}$ of slag depth, is tentatively proposed until a satisfactory measurement can be made by another technique.

\section{CALCULATIONS ON DIFFUSION OF HYDROGEN IN URANIUM ROD}

The possibility of removing hydrogen from uranium by degassing at elevated temperatures and at low hydrogen pressures was considered. The rate of pickup or removal of hydrogen in solution in uranium depends upon the rate of diffusion of hydrogen in the metal at the temperature of interest, assuming there are no diffusion barriers at the surface of the metal. The time to produce a required hydrogen 


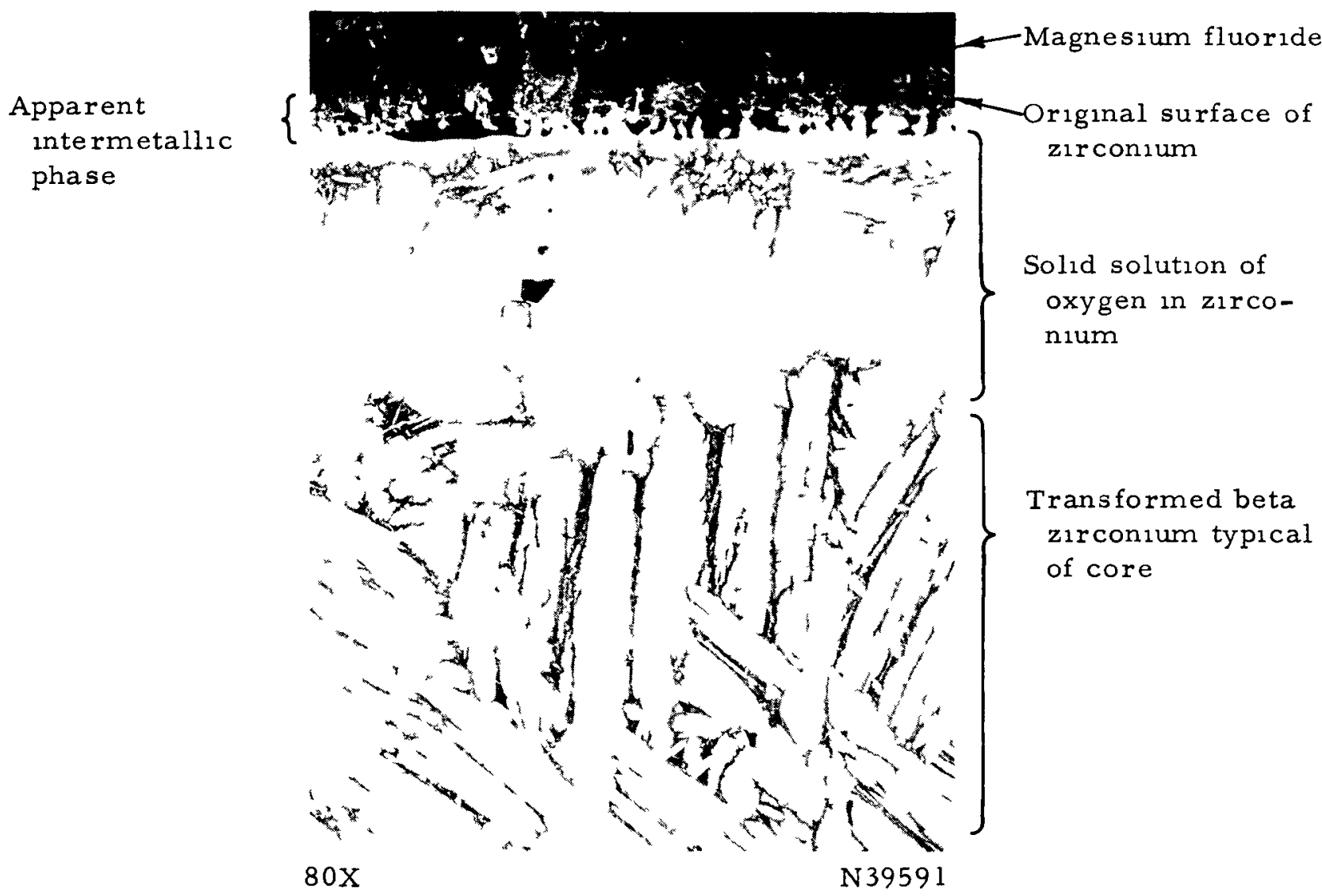

FIGURE 8. PHOTOMICROGRAPH OF ZIRCONIUM SPECIMEN SHOWING REACTION WITH OXYGEN FROM CP MAGNESIUM FLUORIDE 
concentration at a given position within the metal depends upon the boundary conditions, that is, the original hydrogen concentration in the metal and the hydrogen concentration at the surface during the treatment. If the diffusion coefficient for hydrogen in uranium at the desired temperature is known and a specific model (plate, cylinder, or sphere) is as sumed, the time to produce various hydrogen-concentration levels within the model can be calculated. On this basis several calculations were made for a uranium rod 1. 44 in. in diameter and infinitely long. This rod, after certain heat treatments, is machined into a uranium slug with a diameter of 1.36 in. The hydrogen concentration at the surface of the slug must be $2 \mathrm{ppm}$ or less in order to clad it properly. Therefore, the problem is to determine the time required to produce the desired condition.

Calculations were made for several cases in which various boundary conditions and hydrogen levels within the rod were assumed.

Case 1. The assumed initial hydrogen concentration of the uranium rod is $5 \mathrm{ppm}$, which is uniformly distributed throughout the rod. The hydrogen concentration at the surface is zero (zero hydrogen pressure). The diameter of the rod is 1.44 in. (radius is $0.72 \mathrm{in.)}$. Calculations were made to determine the time at $650 \mathrm{C}$ to produce a level of $2 \mathrm{ppm}$ of hydrogen at a diameter of $1.36 \mathrm{in.} \mathrm{(radius} \mathrm{is} 0.68 \mathrm{in}$.). The time to do this was found to be $6 \mathrm{~min}$. The hydrogen-concentration gradient at this time is shown in Figure 9. It is seen that the hydrogen content has been decreased in the outer $(0.2$ in.) portion of the rod. Most of the core remains at the 5-ppm level. It would be expected during cladding a slug (radius of 0.68 in.) prepared from a rod having such a hydrogen gradient that the surface hydrogen would increase above $2 \mathrm{ppm}$ immediately upon heating to elevated temperatures.

Case 2. The as sumptions for this case were the same as for Case 1 above except that the calculations were made to determine the time to produce a level of $2 \mathrm{ppm}$ of hydrogen at a radius of $0.60 \mathrm{in.}$ (arbitrarily chosen). For this case, the time was found to be $48 \mathrm{~min}$. The hydrogen gradient is shown in Figure 10. It is seen that hydrogen is just starting to be removed from the core. The hydrogen concentration at a radius of $0.68 \mathrm{in.}$ (radius of slug) is about $0.65 \mathrm{ppm}$. Such a slug probably could be clad before a concentration of $2 \mathrm{ppm}$ at the surface would be attained.

Case 3. The conditions are the same as for Case 1 except that it was assumed that the sample was degassed in a system with a hydrogen pressure of $258 \mathrm{~mm}$ of mercury, which is equivalent to a hydrogen solubility of $1.2 \mathrm{ppm}$ at $650 \mathrm{C}$. The calculations show that $24 \mathrm{~min}$ is required to produce a gradient with a hydrogen level of 2 ppm at a radius of $0.68 \mathrm{in.}$ The concentration gradient is given in Figure 11 . It is seen that a longer time, $24 \mathrm{~min}$, is required to lower the hydrogen level to $2 \mathrm{ppm}$ at a radius of $0.68 \mathrm{in.}$ when hydrogen is present at the surface, as in Case 3 , than is required in Case $1(6 \mathrm{~min})$, where the concentration of hydrogen is zero at the surface.

Case 4. The initial hydrogen concentration of a uranium rod (0.72-in. radius) is assumed to be $1.2 \mathrm{ppm}$, which is uniformly distributed throughout the rod. The hydrogen concentration at the surface is $25.4 \mathrm{ppm}$, which is equivalent to a saturation potential of $8.6 \mathrm{~atm}$ at $700 \mathrm{C}$. Calculations were made to determine the time to reach 
29

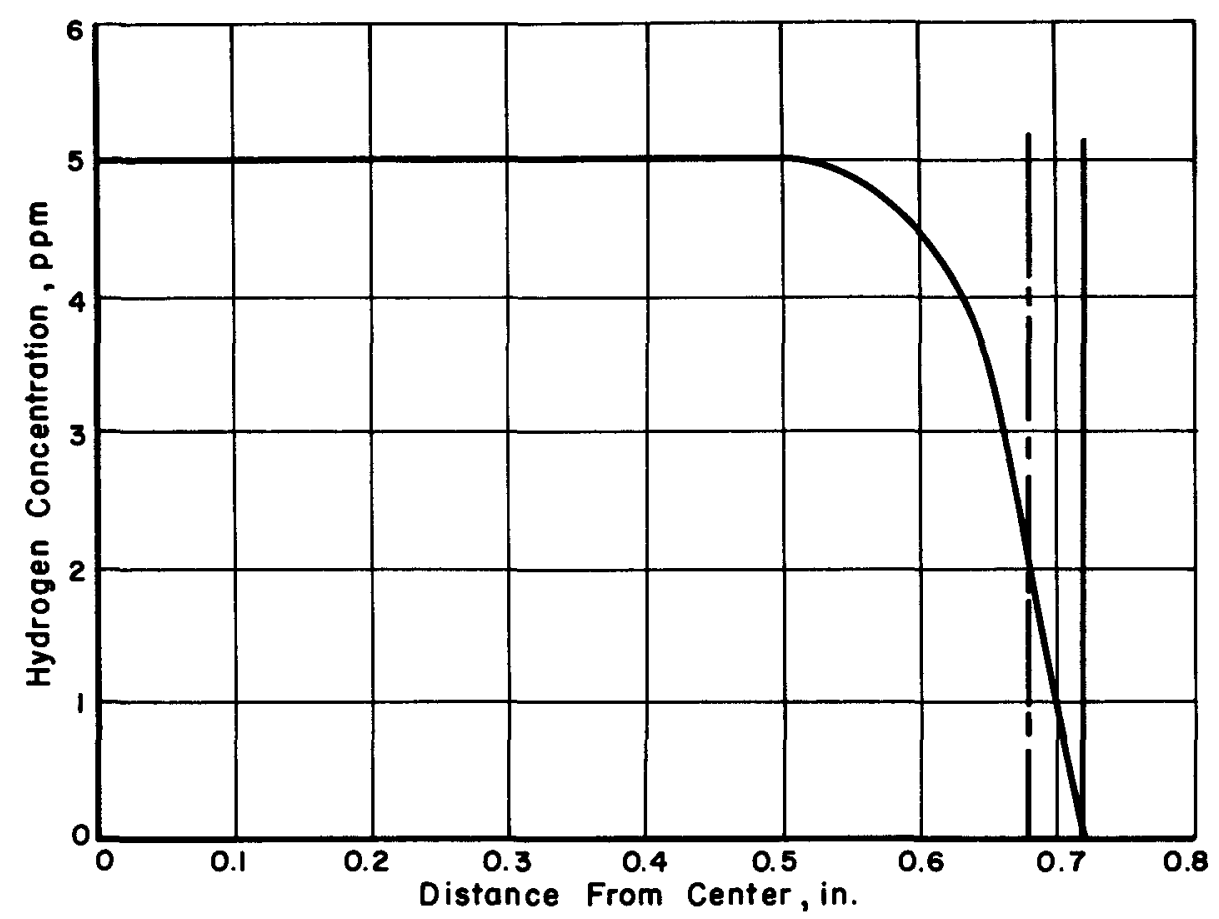

FIGURE 9. HYDROGEN-CONCENTRATION GRADIENT PRODUCED IN A URANIUM CYLINDER AFTER VACUUM DEGASSING 6 MIN AT $650 \mathrm{C}$

Case 1 ; rod radius, 0.72 in.

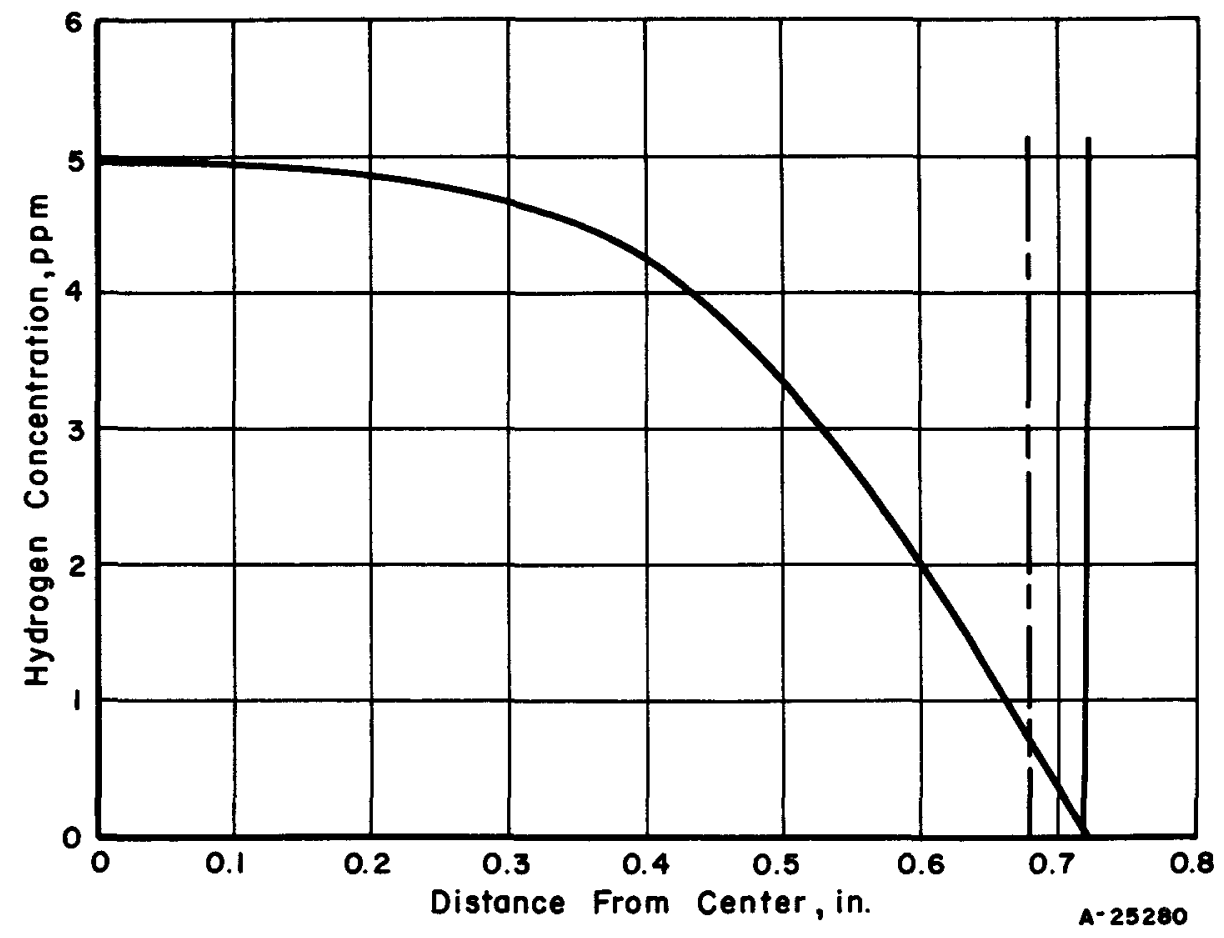

FIGURE 10. HYDROGEN-CONCENTRATION GRADIENT PRODUCED IN A URANIUM CYLINDER AFTER VACUUM DEGASSING 48 MIN AT $650 \mathrm{C}$

Case 2 ; rod radius, 0.72 in. 


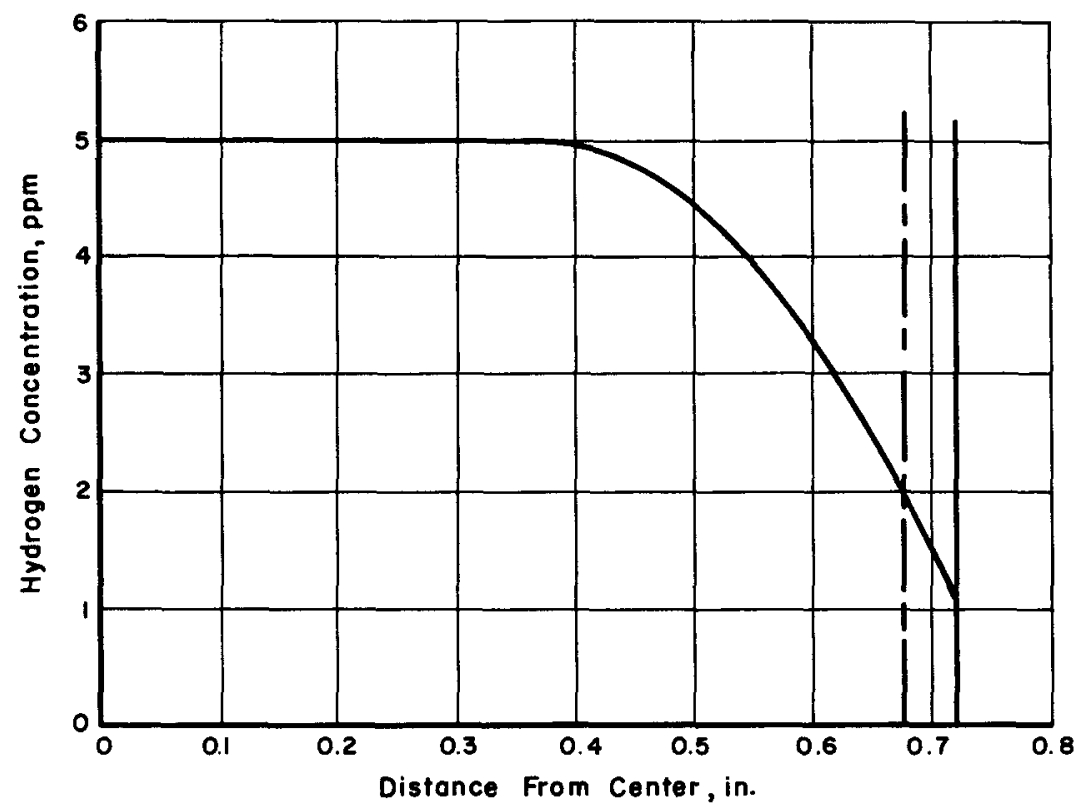

FIGURE 11. HYDROGEN-CONCENTRATION GRADIENT PRODUCED IN A URANIUM CYLINDER AFTER DEGASSING 24 MIN AT $650 \mathrm{C}$

Case 3; concentration of surface is maintained at 1.2 ppm hydrogen; rod radius, $0.72 \mathrm{in.}$

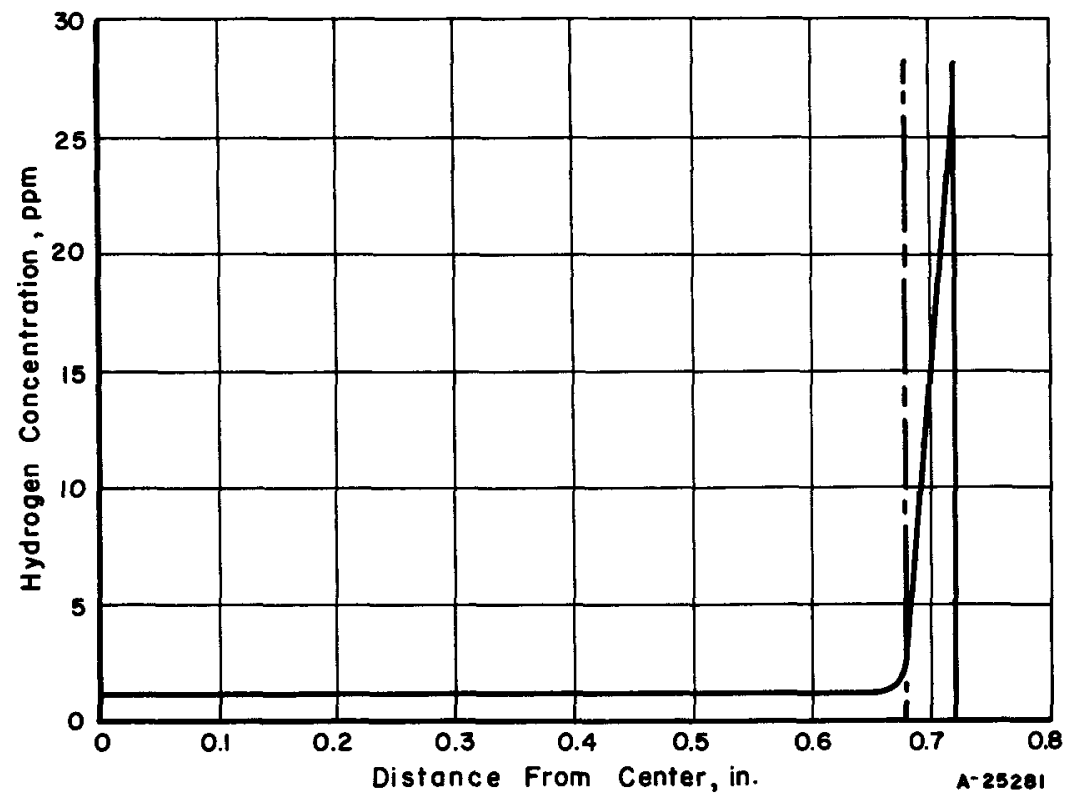

FIGURE 12. HYDROGEN-DIFFUSION GRADIENT PRODUCED IN A URANIUM CYLINDER IN 44 SEC AT $700 \mathrm{C}$

Case 4; hydrogen concentration at surface is maintained at $25.4 \mathrm{ppm}$; rod radius, $0.72 \mathrm{in}$. 
a level of $2 \mathrm{ppm}$ hydrogen at a radius of $0.68 \mathrm{in}$. The time was calculated to be $44 \mathrm{sec}$. The concentration gradient is shown in Figure 12. It is seen that the hydrogen content increases very rapidly from the $1.2-\mathrm{ppm}$ level to $2 \mathrm{ppm}$ at the 0.68 -in. radius. Some additional calculations were made to determine the effective hydrogen pressures of a salt bath, as follows in Case 5 .

Case 5. The assumed initial hydrogen concentration of a uranium rod, 0.72 in. in radius, is $2 \mathrm{ppm}$, uniformly distributed throughout the specimen. The rod is heated in a salt bath at $730 \mathrm{C}$ for $15 \mathrm{~min}$. At the end of this time, hydrogen concentrations of either 5,10 , or $15 \mathrm{ppm}$ are found at a radius of $0.68 \mathrm{in}$. Calculations were made to determine the effective hydrogen pressure at the surface for each hydrogen concentration at $0.68 \mathrm{in.}$, assuming that the hydrogen concentration in the core of the specimen did not increase above $2 \mathrm{ppm}$. The results are tabulated below:

\begin{tabular}{cc}
$\begin{array}{c}\text { Hydrogen Concentration at } \\
\text { Radius of } 0.68 \mathrm{In} ., \mathrm{ppm}\end{array}$ & $\begin{array}{c}\text { Effective Pressure at } \\
\text { Surface of Rod, atm }\end{array}$ \\
\hline 5 & 0.37 \\
10 & 1.7 \\
15 & 3.6
\end{tabular}

These pressures are in a range that might be expected from knowledge of actual fabrication techniques. However, these calculations are based on one point of the hydrogen gradient. If more data of hydrogen concentrations at various radii of a rod treated in the salt bath were obtained, calculations could be made to establish more definitely the effective hydrogen pressures of the salt bath.

In addition to the cases described above, the times required to degas uranium cylinders of different diameters in a vacuum at different temperatures were calculated. Table 2 lists the calculated times required to remove 99 per cent of the hydrogen from uranium cylinders with diameters of $1,1-1 / 2,2,7$, and $1 \varepsilon$ in., respectively.

\section{TABLE 2. CALCULATED TIMES REQUIRED TO DEGAS URANIUM SAMPLES OF DIFFERENT DIAMETERS(a)}

\begin{tabular}{|c|c|c|c|c|c|c|}
\hline \multirow{3}{*}{$\begin{array}{c}\text { Diameter, } \\
\text { in. }\end{array}$} & \multicolumn{6}{|c|}{ Time at Indicated Temperature, hr } \\
\hline & \multicolumn{3}{|c|}{ Alpha Range } & \multicolumn{2}{|c|}{ Beta Range } & \multirow{2}{*}{$\begin{array}{c}\text { Gamma(b), } \\
1000 \mathrm{C}\end{array}$} \\
\hline & $400 \mathrm{C}$ & $500 \mathrm{C}$ & $600 \mathrm{C}$ & $\overline{700 \mathrm{C}}$ & $750 \mathrm{C}$ & \\
\hline 1 & 90 & 30 & 14 & 6 & 3 & $<0.1$ \\
\hline 1.5 & 202 & 68 & 30 & 4 & 7 & 0.7 \\
\hline 2 & 360 & 122 & 55 & 25 & 13 & 1 \\
\hline 7 & 4400 & 1500 & 670 & 300 & 157 & 14 \\
\hline 18 & 28,900 & 9750 & 4370 & 1950 & 1030 & 89 \\
\hline
\end{tabular}

(a) Based upon diffusion coefficients reported in Reference (5).

(b) Based upon diffusion coefficient extrapolated from beta range. 


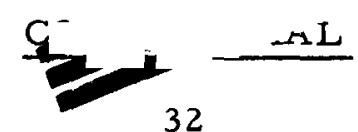

32

The data in the table may be used to calculate time required to remove fractions other than 99 per cent of the total gas content. This is done by multiplying the appropriate fraction by the time listed in the table. For example, to calculate the times required to remove 25,50 , or 75 per cent of the total gas, one would take $1 / 4,1 / 2$, or $3 / 4$, respectively, of the time listed.

\section{REFERENCES}

(1) Guay, A. E., "A Study of the Hydrogen Content and Associated Variables in the Production and Heat Treating of Uranium", TID-7526 (Part 3), pp 52 to 64 (February, 1957), Secret.

(2) Mallett, M. W., Gerds, A. F., and Griffith, C. B., "Determination of Hydrogen in Magnesium, Lithium, and Magnesium-Lithium Alloys", Analytical Chemistry, 25, 116 (1953).

(3) A description of the apparatus is given in, "Kinetics of the Reaction of Hydrogen With Zirconium", Belle, Jack, Cleland, B. B., and Mallett, M. W., J. Electrochem. Soc., 101, 211 (1954).

(4) Katz, J. J., and Rabinowitch, E., The Chemistry of Uranium, National Nuclear Energy Series, McGraw-Hill Book Company, Inc., New York (1951), p 184.

(5) Mallett, M. W., and Trzeciak, M. J., "Hydrogen-Uranium Relationships", Accepted for publication in Transactions ASM (1957).

MJ T:MWM/apo

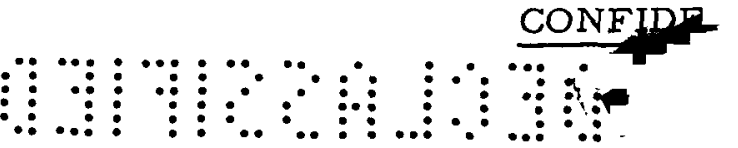

